\title{
EDITORIAL
}

\section{The Research Works Act: a comment}

\author{
Naomi Attar* and GB Editorial Team
}

It's been a tale of two 'opens'; recent events in US political life suggest a reconciliation with the concept of open marriage but a relationship with open access to scientific research that may be headed for splitsville.

In a rare feat of bipartisanship during a Congress famed for partisan pettiness, the Research Works Act (RWA) has received cross-party sponsorship in the House and is now being heard in Committee. The Act, in its own words, seeks to prevent Federal agencies from requiring that authors 'assent to network dissemination of a privatesector research work'. Translation? It will be illegal for Federally funded research grants to have open access strings attached. This includes a bar on policies insisting on deposition in public repositories; in fact, it will be illegal to 'cause', 'permit' or 'authorize' such a deposition.

RWA has not attracted the same volume of headlines as the equally controversial SOPA (Stop Online Piracy Act), which was another recent bill pertaining to internet freedoms. But although the opponents of RWA cannot rival the political and global reach of the likes of Google and Wikipedia, a spirited, academia-led campaign against RWA is underway on the blogosphere and Twitter. As with many grassroots protests in the social media era, the RWA rebutters have mixed a sense of genuine outrage with mischievous and irreverent humor.

One notable line of campaigning has been to instigate a boycott of publishers deemed to be supportive of RWA. The boycott includes refusing to peer review manuscripts, in addition to submitting manuscripts only to publishers opposed or indifferent to RWA. Particular ire has been reserved for publishing houses thought to be proactive in their RWA support, either through lobbying or in terms of financial backing provided to Washington politicos. As one company singled out for approbation is a competitor of this journal's publisher, there is an undoubted temptation to indulge in a little schadenfreude and jump on the boycott bandwagon. However, while researchers are of course at liberty to submit to and peer review for whichever journals they choose (and on whatever grounds they choose), it seems that the focus on

*Correspondence: naomi.attar@genomebiology.com

Genome Biology, BioMed Central, 236 Gray's Inn Road, London WC1X 8HB, UK publishers is misplaced. Companies should be expected to make representations, by legal means, on behalf of what they perceive to be their best interests (admittedly, a boycott may influence these perceptions); instead, the war for open access must be waged against the Congressmen, accountable to the People, who are driving RWA forward.

Looking into the US from the other side of the Atlantic, Federal funding for scientific research can only be viewed through a green mist of envy. The contribution of these funds to global science is remarkable (just take a look at a list of Nobel Prize winners, and note how many institutional affiliations are in the US), and is a record of which US tax payers should be justly proud. This contribution is not paralleled by any other government. Furthermore, efforts by funding agencies to make the benefits of research as widely available as possible - including to those outside the US - are laudable. It seems to be a truism that maximizing access to the results of scientific endeavor is in the best interests of further scientific progress, and so offers the best value to the taxpayer. So why would the representatives of the very same taxpayer seek to restrict access to this research, and by the same measure subsidize the publishing industry with money diverted away from scientists? It defies belief to imagine that these Congressmen are arguing for their constituents to pay exorbitant prices simply to read articles that they themselves have paid for with their tax dollars.

So what is the defense? Supporters of RWA pitch it as a battle for the free market; in the words of the Association of American Publishers, its motivation is the 'freedom from regulatory interference for [the] private sector.' Of course, this is quite the opposite of what RWA actually represents, which is additional government regulation contrary to the spirit of the free market. In fact, market forces scare traditional publishing models, because left to their own devices they will arrive at the most efficient use of capital, which is undoubtedly, for the funding agencies, open access publishing. Given that Federal funding ultimately pays for both access to publications and publishing costs, the best value option is an open access model. This is because the cost of publication should not vary according to access level, only the size of the audience able to access the material. To prevent Federal agencies from pursuing what is therefore a no-brainer 
option, RWA is designed to skew the market; it leaves the decision of which model to publish manuscripts under to individual authors, thereby creating a disconnect between the source of capital and the choice of how it is spent. No freely operating market would tolerate those paying for the product (the taxpayers) being barred from access to its benefits.

One component of the defense put forward for RWA is particularly provocative, and warrants more detailed attention. Here's the Association of American Publishers again: RWA will protect 'millions of dollars invested by publishers in... operational funding of independent peer review by specialized experts.' Publishers would do well to remember that academics offer a peer review service free of charge, and so to focus on peer review as a publisher-added value, even though there are undoubtedly publisher-incurred costs to this process, is unnecessarily antagonistic.
Congress must judge RWA in the true spirit of the free market, the taxpayer and the great tradition of American science. Open access publishing is an economic inevitability. It's time to get on board.

\section{Competing interests}

As Genome Biology publishes research under an exclusively open access model, the journal is unashamed to oppose any legislation aiming to restrict the fruits of scientific research to a limited audience.

\section{Your views}

Genome Biology would be interested to hear any dissenting views on this Editorial, or indeed any positive feedback. Tell us your own perspective either by posting a comment on this article or by including our @GenomeBiology handle in a tweet.

Published: 20 February 2012

doi:10.1186/gb-2012-13-2-416

Cite this article as: Attar N, and GB Editorial Team: The Research Works Act: a comment. Genome Biology 2012, 13:416. 